\title{
Successful surgical treatment for recurrent cardiac fibroma 21 years after resection
}

\author{
Kunio Kusajima', Hiroki Hata1*, Tomoyuki Fujita', Yusuke Shimahara', Shunsuke Sato', Hatsue Ishibashi-Ueda² \\ and Junjiro Kobayashi ${ }^{1}$
}

\begin{abstract}
Cardiac fibromas are rare benign tumors usually seen in the pediatric population. Generally, long-term survival after surgical resection is favorable, and recurrence of fibroma has been hardly reported. Herein, we report a case of a 34-year-old woman who presented with ventricular tachycardia 21 years after resection of a cardiac fibroma and was found to have a recurrent giant cardiac fibroma. We performed a complete resection of the recurrent fibroma. At the 2-year follow-up, she remains asymptomatic with no evidence of ventricular tachycardia or recurrence of fibroma.
\end{abstract}

Keywords: Cardiac tumor; Cardiac fibroma; Recurrence; Arrhythmia; Surgery

\section{Background}

Cardiac fibromas are rare benign tumors predominantly seen in the pediatric population [1]. Patients can be asymptomatic or present with palpitations, cardiac murmur, syncope, arrhythmias, symptoms of congestive heart failure, or sudden death. The clinical presentation depends on tumor location and size [2-5].

Because cardiac fibromas rarely regress spontaneously [6], surgical resection should be considered in symptomatic cases. If possible, complete resection is usually recommended; otherwise, partial resection, heart transplantation, or conservative management is also advocated [3]. Generally, long-term survival after surgical resection is favorable and recurrence has been scarcely reported $[3,5,6]$. In this report, we describe a case of successful resection of a recurrent giant fibroma. To the best of our knowledge, this is the first report of successful surgical treatment of a recurrent cardiac fibroma.

\section{Case presentation}

A 34-year-old woman complained of palpitations and consulted a doctor. She had a history of resection of a right ventricular (RV) fibroma 21 years ago at another hospital. At the initial operation, complete resection was impossible because of its difficulty. Five years after the operation, follow-up was ceased because she did not have any cardiac symptoms.

When she was referred to our center, electrocardiography showed sustained ventricular tachycardia (VT) (Fig. 1), which was well suppressed with oral amiodarone. Transthoracic echocardiography showed a giant mass $(80 \times 80 \times 60 \mathrm{~mm})$ located in the intraventricular septum (IVS) (Fig. 2) and the posterior wall of the left ventricle (LV). General ventricular wall motion was good (LV ejection fraction of 60\%). Tricuspid regurgitation (TR) and mitral regurgitation (MR) were trivial. Enhanced cardiac computed tomography scan revealed that the mass contained calcification and was poorly enhanced. Cardiac magnetic resonance imaging showed that the mass oppressed the LV cavity with low tumor signal on the T2-weighted image (Fig. 3). Positron emission tomography with fluorine-18 fluorodeoxyglucose showed no abnormal uptake within the tumor. These findings strongly suggested the diagnosis of recurrent fibroma. The tumor was huge, oppressing the LV cavity, and was regarded to be the cause of VT. Therefore, we arranged surgical resection.

\footnotetext{
* Correspondence: hatahiro@ncvc.go.jp

1 Department of Cardiovascular Surgery, National Cerebral and Cardiovascular Center, Suita, Japan

Full list of author information is available at the end of the article
} 


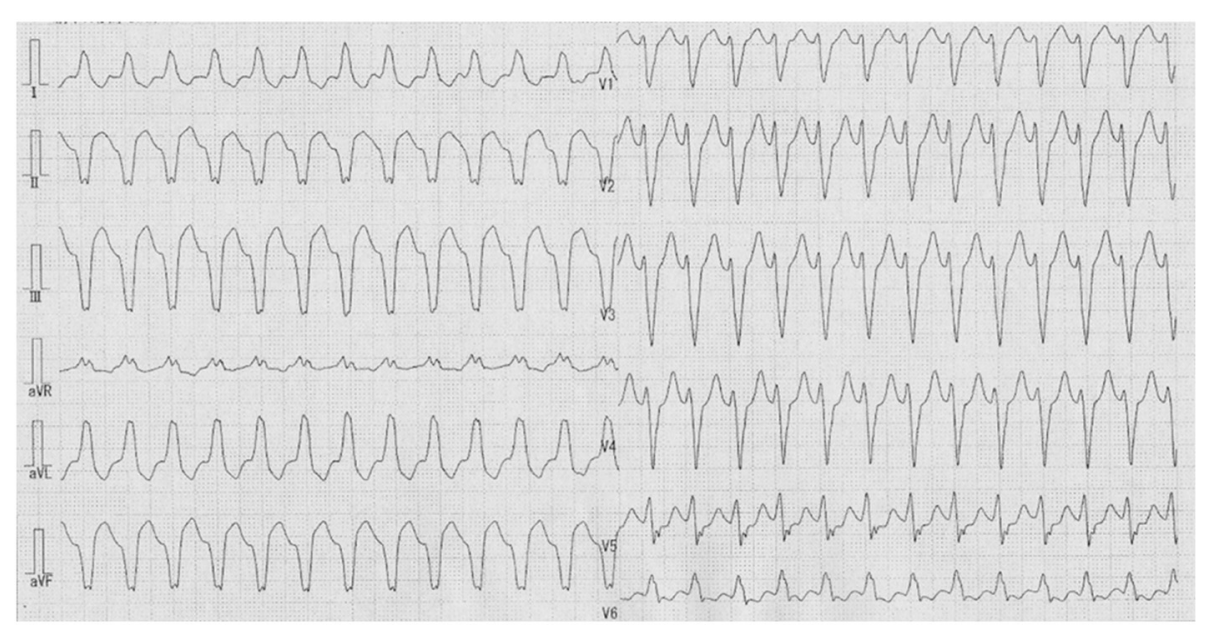

Fig. 1 Electrocardiogram at admission showed ventricular tachycardia

Complete surgical resection was performed through median sternotomy with cardiopulmonary bypass under cardioplegic arrest. The gray-white tumor appeared to originate from the IVS involving the apex and the LV posterior wall. The solitary tumor was completely excised by sharp dissection together with the feeding artery (Fig. 4). The defect of the IVS, sized $5 \times 15 \mathrm{~mm}$, was closed with Teflon felt-pledgeted 4-0 polypropylene mattress sutures. The giant remnant cavity and ventricle wall were closed with double layers of 4-0 polypropylene running sutures. Cardiopulmonary bypass time and aortic cross clamp time were 113 and $64 \mathrm{~min}$, respectively. The patient was easily weaned from cardiopulmonary bypass, and intraoperative transesophageal echocardiography showed good ventricular contraction without TR, MR, or shunt flow through the IVS. The excised specimen

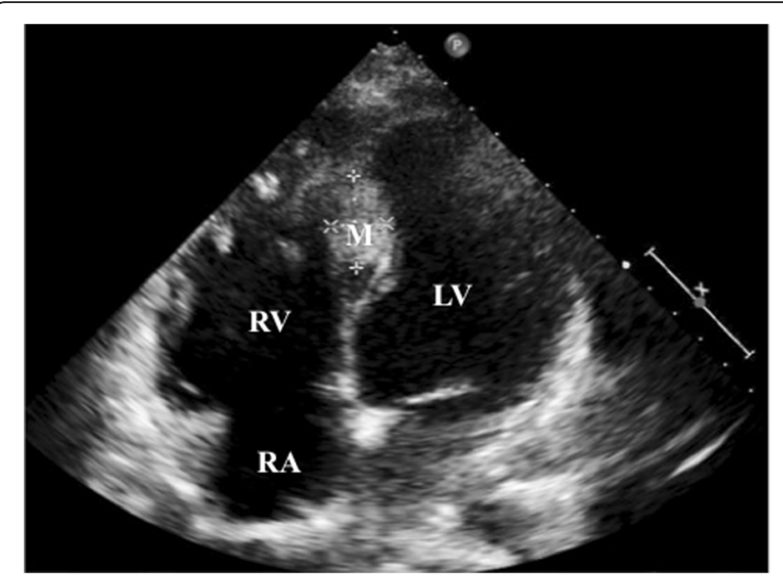

Fig. 2 Transthoracic echocardiography image showing a mass in the intraventricular septum. $R A$ right atrium, $R V$ right ventricle, $L V$ left ventricle, $M$ mass showed a well-circumscribed solid firm mass without capsule and measured $80 \times 80 \times 60 \mathrm{~mm}$, weighing $140 \mathrm{~g}$. Most part of the tumor composed of hyalinized acellular fibrous tissue with focal calcification. Sporadic part showed fibroblast proliferation without malignancy. Pathologic examination confirmed the diagnosis of benign cardiac fibroma (Fig. 5) and total extirpation. Ventricular tachycardia was not observed on continuous electrocardiographic monitoring. Two years after the operation, the patient could cease amiodarone and remained asymptomatic without VT. Transthoracic echocardiography showed good ventricular contraction without residual shunt flow or recurrence of fibroma.

\section{Discussion}

Cardiac fibromas are rare but benign tumors and more than $80 \%$ of them occur in the pediatric population [2, 7]. Long-term results after surgical resection were generally reported to be favorable $[1,3]$. Therefore, medical follow-up is often ceased once the patient becomes an adult. There has never been a report of a recurrent case after surgical resection to date [3]. In the present case, complete resection was not performed at the initial operation because of diffuse involvement of the fibroma into the right ventricular trabeculae. At this time of operation, the tumor appeared to originate from the right ventricular septum, involving the apex and the posterior wall of LV. Therefore, we believed that this tumor is a recurrent fibroma proliferating from the residual lesion.

The majority of fibromas are found in the LV or RV wall, and fewer than $20 \%$ are detected in the IVS [5]. Fibromas can cause lethal arrhythmia, valve regurgitation, and ventricular inflow/outflow tract obstruction depending on their location and size $[4,8]$. If left untreated, 

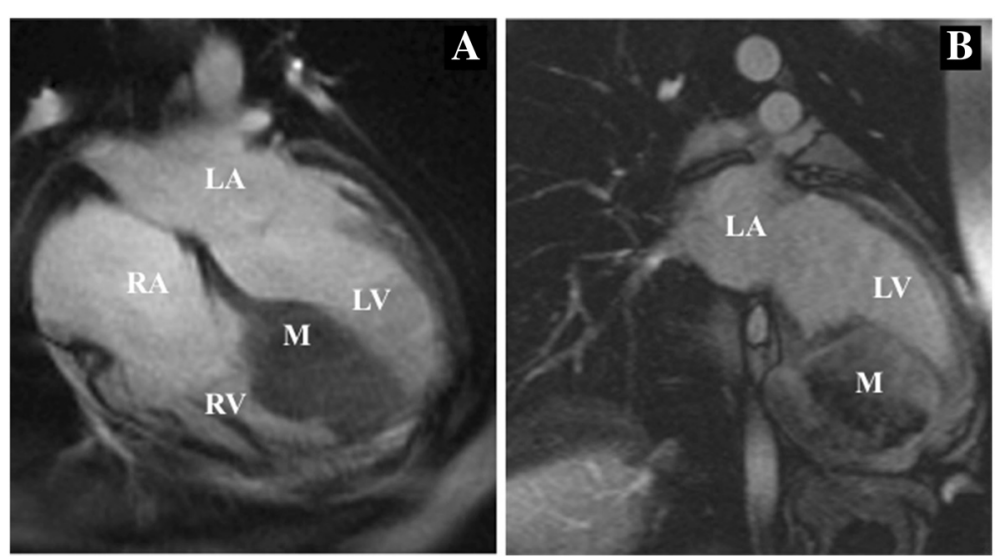

Fig. 3 Cardiac magnetic resonance images. a A low-density mass located in the intraventricular septum on the T2-weighted image. b The mass involved the apex and the posterior wall of the left ventricle (LV) and oppressed the LV cavity. RA right atrium, RV right ventricle, $L A$ left atrium, $L V$ left ventricle, $M$ mass

fibromas can increase the risk of fatality. Therefore, surgical resection is recommended, especially in symptomatic cases. Basically complete resection is recommended first. But, partial resection can be an acceptable option when papillary muscle, valvular, and/or ventricular function might be reduced after complete resection $[3,7]$.

\section{Conclusion}

In conclusion, we report the first case of a successful complete resection of a recurrent cardiac fibroma 21 years after the initial operation. Recurrence should be considered when new-onset arrhythmia or cardiac murmur is noted in a patient with a history of fibroma resection, especially without complete resection. Although partial resection may be acceptable to preserve valvular

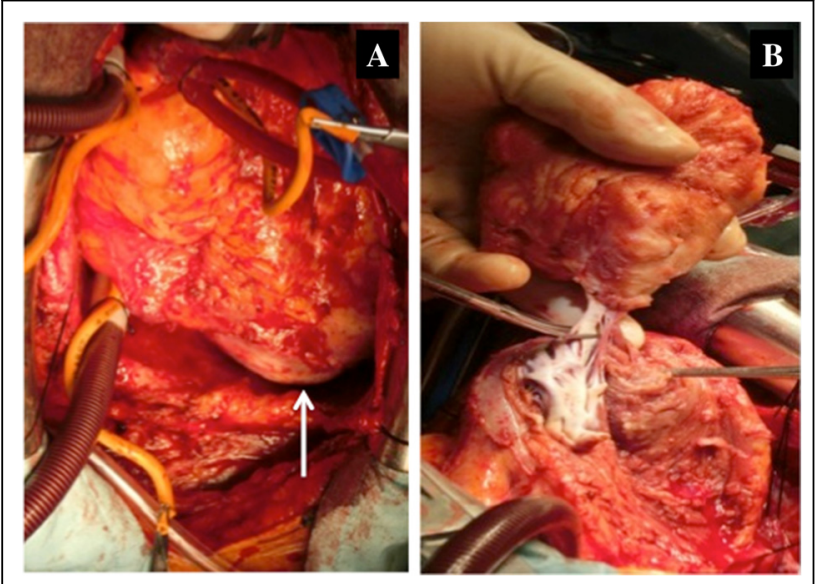

Fig. 4 a Intraoperative view (patient's head is at the top). The gray-white tumor located in the apex and the LV posterior wall (arrow). b The solid and solitary tumor was completely excised by sharp dissection and/or ventricular function, complete resection is preferable to eliminate the risk of recurrence.

\section{Consent}

Written informed consent was obtained from the patient for publication of this case report and any accompanying images. A copy of the written consent is available for review by the Editor-in-Chief of this journal.

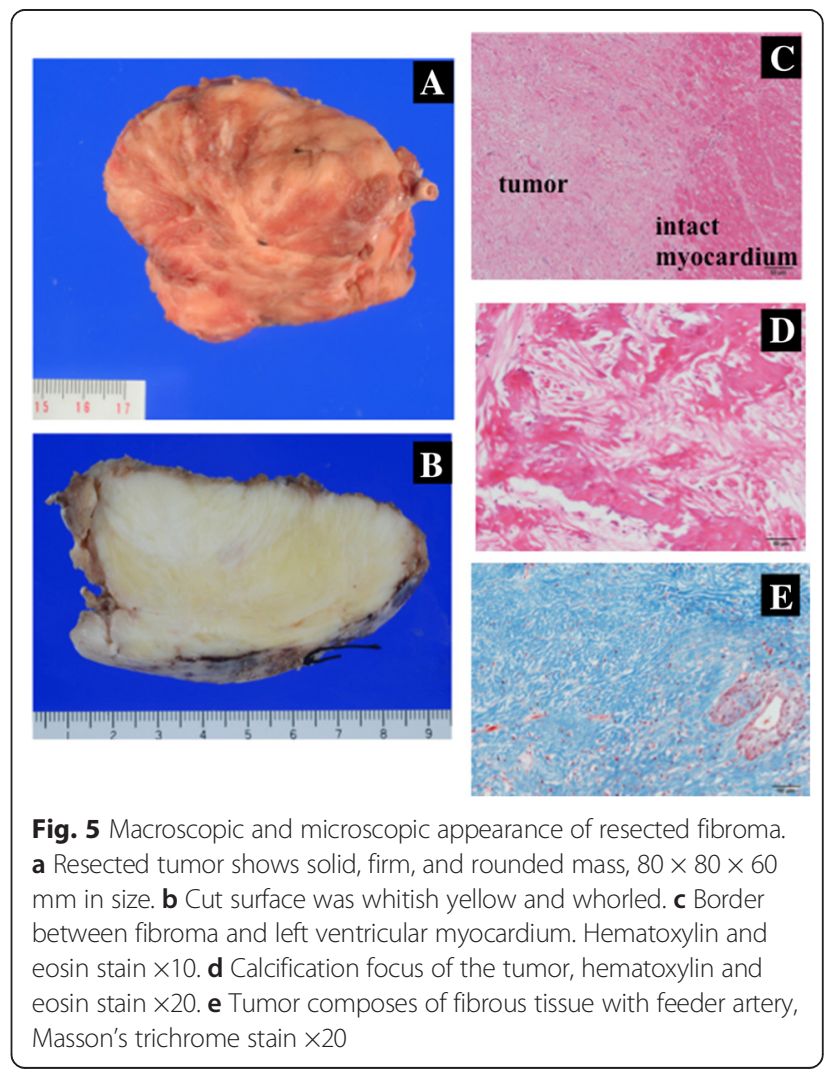




\section{Competing interests}

The authors declare that they have no competing interests.

\section{Authors' contributions}

$\mathrm{JK}, \mathrm{HH}$, and KK performed the recent operation. They together with TF designed and drafted the manuscript. $\mathrm{KK}$ and $\mathrm{HH}$ wrote and revised the manuscript. YS and SS collected the data and analyzed the images of echocardiogram and magnetic resonance image. HIU analyzed the resected tissue histopathologically. All authors read and approved the final manuscript.

\section{Author details}

'Department of Cardiovascular Surgery, National Cerebral and Cardiovascular Center, Suita, Japan. ${ }^{2}$ Department of Pathology, National Cerebral and Cardiovascular Center, Suita, Japan.

Received: 24 March 2015 Accepted: 5 May 2015

Published online: 16 May 2015

\section{References}

1. Padalino MA, Vida VL, Boccuzzo G, Tonello M, Sarris GE, Berggren $H$, et al. Surgery for primary cardiac tumors in children: early and late results in a multicenter European Congenital Heart Surgeons Association study. Circulation. 2012;126:22-30.

2. Parmley LF, Salley RK, Williams JP, Head 3rd GB. The clinical spectrum of cardiac fibroma with diagnostic and surgical considerations: noninvasive imaging enhances management. Ann Thorac Surg. 1988;45:455-65.

3. Cho JM, Danielson GK, Puga FJ, Dearani JA, McGregor CG, Tazelaar HD, et al. Surgical resection of ventricular cardiac fibromas: early and late results. Ann Thorac Surg. 2003;76:1929-34.

4. Chen Y, Sun J, Chen W, Peng Y, An Q. Third-degree atrioventricular block in an adult with a giant cardiac fibroma. Circulation. 2013;127:e522-4.

5. Torimitsu S, Nemoto T, Wakayama M, Okubo Y, Yokose T, Kitahara K, et al. Literature survey on epidemiology and pathology of cardiac fibroma. Eur J Med Res. 2012;17:5.

6. Nwachukwu H, Li A, Nair V, Nguyen E, David TE, Butany J. Cardiac fibroma in adults. Cardiovasc Pathol. 2011;20:e146-52.

7. Henaine R, Adam E, Azarnoush K, Yashimura N, Cannesson M, Millon A, et al. Is subtotal resection of a right ventricular fibroma a valid surgical option? J Thorac Cardiovasc Surg. 2009;137:e32-4.

8. Grinda JM, Macé L, Dervanian P, Neveux JY. Obstructive right ventricular cardiac fibroma in an adult. Eur J Cardiothorac Surg. 1998;13:319-21.

\section{Submit your manuscript to a SpringerOpen ${ }^{\circ}$ journal and benefit from:}

- Convenient online submission

- Rigorous peer review

- Immediate publication on acceptance

- Open access: articles freely available online

- High visibility within the field

- Retaining the copyright to your article

Submit your next manuscript at springeropen.com 